\title{
Evaluation of Insulin Medium or Chondrogenic Medium on Proliferation and Chondrogenesis of ATDC5 Cells
}

\author{
Yongchang Yao, ${ }^{1,2}$ Zhichen Zhai, $^{1,2}$ and Yingjun Wang ${ }^{1,2}$ \\ ${ }^{1}$ School of Materials Science and Engineering, South China University of Technology, Guangzhou 510641, China \\ ${ }^{2}$ National Engineering Research Center for Tissue Restoration and Reconstruction, Guangzhou 510006, China \\ Correspondence should be addressed to Yingjun Wang; imwangyj@163.com
}

Received 26 December 2013; Revised 4 March 2014; Accepted 8 March 2014; Published 10 April 2014

Academic Editor: Zhi-Yong Zhang

Copyright (c) 2014 Yongchang Yao et al. This is an open access article distributed under the Creative Commons Attribution License, which permits unrestricted use, distribution, and reproduction in any medium, provided the original work is properly cited.

\begin{abstract}
Background. The ATDC5 cell line is regarded as an excellent cell model for chondrogenesis. In most studies with ATDC5 cells, insulin medium (IM) was used to induce chondrogenesis while chondrogenic medium (CM), which was usually applied in chondrogenesis of mesenchymal stem cells (MSCs), was rarely used for ATDC5 cells. This study was mainly designed to investigate the effect of IM, CM, and growth medium (GM) on chondrogenesis of ATDC5 cells. Methods. ATDC5 cells were, respectively, cultured in IM, CM, and GM for a certain time. Then the proliferation and the chondrogenesis progress of cells in these groups were analyzed. Results. Compared with CM and GM, IM promoted the proliferation of cells significantly. CM was effective for enhancement of cartilage specific markers, while IM induced the cells to express endochondral ossification related genes. Although GAG deposition per cell in CM group was significantly higher than that in IM and GM groups, the total GAG contents in IM group were the most. Conclusion. This study demonstrated that CM focused on induction of chondrogenic differentiation while IM was in favor of promoting proliferation and expression of endochondral ossification related genes. Combinational use of these two media would be more beneficial to bone/cartilage repair.
\end{abstract}

\section{Introduction}

Cartilage is a very complex and avascular tissue, which would lead to the limited capacity for self-repair once cartilage is damaged. Tissue engineering and regenerative medicine provide an excellent way for cartilage repair. Although, in principle, autologous chondrocytes are the best cells for cartilage tissue engineering applications, it is difficult to acquire sufficient chondrocytes for tissue repair because of the damage to the donor, poor proliferation in vitro, and so on $[1,2]$. In this context, stem cells including embryonic and mesenchymal cells appear as a promising alternative and are widely studied for cartilage regeneration [3].

The issue of how to induce the differentiation of stem cells efficiently and keep the long-lasting function is still not addressed. Differentiation capability of stem cells will be varied with different conditions, such as cell source and passage [4], causing different even conflicting results. For instance, TGF- $\beta 3$, which is referred to as a chondrogenesis-inducing factor in most circumstances, may not promote chondrogenesis or even inhibit it in some cases $[5,6]$. Therefore, researchers endeavored to look for another stable model cell line with such properties as indefinite and rapid proliferation as well as homogenous stability. Recently, lots of cell lines, such as C3H10T1/2 [7], ATDC5 [8], RCJ3.1C5 [9], CFK2 [10], C2C12 [11], MG63 [12], and MC3T3-E1 [13], have been widely used for the study of chondrogenesis and osteogenesis. ATDC5 was derived from AT805 teratocarcinoma cell line in 1990 by Atsumi et al. [8]. Since then, more and more studies have demonstrated that ATDC5 cell line had nearly the same characteristic of chondrogenesis as mesenchymal stem cell. As the ATDC5 cell line was superior in chondrocytic differentiation to C3H10T1/2 and RJC3.1 chondrogenic cell lines [8], it was well acknowledged as an in vitro chondrogenic model.

Insulin medium (IM) was used in most studies with ATDC5 cells for chondrocyte differentiation $[7,8,14]$. 
TABLE 1: Primers used in this study.

\begin{tabular}{lllrc}
\hline Primer & Forward sequence & Reverse sequence & Amplicon & Access number \\
\hline Hprt & CTGGTGAAAAGGACCTCTCGAA & CTGAAGTACTCATTATAGTCAAGGGCAT & 110 & NM_013556.2 \\
Ppia & CGCGTCTCCTTCGAGCTGTTG & TGTAAAGTCACCACCCTGGCACAT & 150 & NM_008907.1 \\
Col2 & AGGGCAACAGCAGGTTCACATAC & TGTCCACACCAAATTCCTGTTCA & 171 & NM_031163.3 \\
Agn & AGTGGATCGGTCTGAATGACAGG & AGAAGTTGTCAGGCTGGTTTGGA & 105 & NM_007424.2 \\
Col1 & ATGCCGCGACCTCAAGATG & TGAGGCACAGACGGCTGAGTA & 153 & NM_007742.3 \\
ColX & TTCTGCTGCTAATGTTCTTGACC & GGGATGAAGTATTGTGTCTTGGG & 115 & NM_009925.4 \\
ALP & TGCCTACTTGTGTGGCGTGAA & TCACCCGAGTGGTAGTCACAATG & 164 & NM_007431.2 \\
OC & AGCAGCTTGGCCCAGACCTA & TAGCGCCGGAGTCTGTTCACTAC & 178 & NM_007541.2 \\
Runx2 & CACTGGCGGTGCAACAAGA & TTTCATAACAGCGGAGGCATTTC & 144 & NM_009820.4 \\
Dlx5 & TACAACCGCGTCCCGAGT & AATAGTCCTGGGTTTACGAA & 108 & NM_010056.2 \\
Osx & CGTCCTCTCTGCTTGAGGAA & CTTGAGAAGGGAGCTGGGTA & 196 & NM_130458.3 \\
VEGF & ACGCATTCCCGGGCAGGTGAC & TCTTCCGGGCTTGGCGATTTAG & 93 & NM_009505.4 \\
\hline
\end{tabular}

Tare et al. [15] reported that chondrogenic medium (CM), commonly used for chondrogenesis of MSCs and other stem cells, was effective for chondrocyte differentiation of ATDC5. In this study, ATDC5 cells were cultured in IM, CM, and growth medium (GM) to evaluate the effect of IM and CM on chondrogenesis of ATDC5 cells. Quantitative RT-PCR (qRTPCR) and histological staining were performed to confirm chondrogenic differentiation of ATDC5.

\section{Materials and Methods}

2.1. Cell Culture. ATDC5 cells were cultured in GM containing 1:1 mixture of Dulbecco's modified Eagle's medium and Ham's F-12 medium supplemented with 5\% fetal bovine serum (Invitrogen) in culture flasks at $37^{\circ} \mathrm{C}$ under $5 \% \mathrm{CO}_{2}$. The culture medium was changed every 3 days.

\subsection{Differentiation of ATDC5 Cells Induced by Different} Medium. ATDC5 cells were cultured in 24-well plates with GM, IM, and CM for 21 days. The ingredients of the abovementioned medium were shown as follows: CM consisted of high-glucose Dulbecco's modified Eagle medium (HDMEM) (Gibco) supplemented with $10 \mathrm{ng} / \mathrm{mL}$ recombinant human transforming growth factor- $\beta 3$ (TGF- $\beta 3$ ) (Peprotech), $100 \mathrm{nM}$ dexamethasone (Sigma), $50 \mu \mathrm{g} / \mathrm{mL}$ ascorbic acid 2-phosphate (Sigma), $1 \mathrm{mM}$ sodium pyruvate (Amersco), $40 \mu \mathrm{g} / \mathrm{mL}$ proline (Biosharp), and ITS+ premix (BD; final concentrations: $6.25 \mu \mathrm{g} / \mathrm{mL}$ bovine insulin, $6.25 \mu \mathrm{g} / \mathrm{mL}$ transferrin, $6.25 \mu \mathrm{g} / \mathrm{mL}$ selenous acid, $5.33 \mu \mathrm{g} / \mathrm{mL}$ linoleic acid, and $1.25 \mathrm{mg} / \mathrm{mL}$ bovine serum albumin); IM was GM supplementing with $10 \mu \mathrm{g} / \mathrm{mL}$ bovine insulin (Sigma). The density of cells in each well was $5 \times 10^{4}$ cells.

For the experiment to select optimal TGF- $\beta 3$ concentration for chondrogenesis of ATDC5 cells, the following concentrations of TGF- $\beta 3,0,2,5,10,20$, and $50 \mathrm{ng} / \mathrm{mL}$, were used in CM, respectively. Cells with the same original density were cultured in 24-well plates for 14 days.

In all groups, medium was changed every 3 days.

2.3. Cell Proliferation Analysis. Cells in three groups were analyzed at various time points as indicated in the text and figure captions by CCK- 8 and double-strand DNA (dsDNA) for cell quantification.

CCK-8 detection was preformed according to the manufacturer's instruction. Briefly, at each time point, cells were seeded at 96-well plate with 1000 cells per well followed by aspiration of the old medium and replacement with $110 \mu \mathrm{L}$ of fresh medium containing CCK-8 regent (Dojindo, premix $10 \mu \mathrm{L}$ of CCK- 8 every $100 \mu \mathrm{L}$ of medium). After 2 hours of incubation at $37^{\circ} \mathrm{C}$ under $5 \% \mathrm{CO}_{2}$, the absorbance for each sample was determined using a microplate reader set to $450 \mathrm{~nm}$.

PicoGreen (Invitrogen) was used for dsDNA quantification. Cells at each time point were reacted with lysing liquid, which contained $50 \mathrm{mM} \mathrm{Na}{ }_{3} \mathrm{PO}_{4}, 20 \mathrm{mM} \mathrm{N}$-acetyl cysteine, and $28 \mu \mathrm{g} / \mathrm{mL}$ papain, for $16 \mathrm{~h}$ at $60^{\circ} \mathrm{C}$. The lysate was centrifuged at $10000 \mathrm{~g}$ for $10 \mathrm{~min}$ at $4^{\circ} \mathrm{C}$ and the dsDNA concentration of the supernatant was measured by PicoGreen according to the manufacturer's protocol.

2.4. Quantitative Analysis of Glycosaminoglycan (GAG) Synthesis. The GAG content was measured using the 1,9dimethylmethylene blue method [16]. After being cultured under different medium for 21 days, cells were lysed by lysing liquid as described in dsDNA quantification. The 1,9-dimethylmethylene blue (Sigma) colorimetric assay was performed with chondroitin-6-sulfate (Sigma) as a standard. The results of GAGs were normalized to dsDNA content.

2.5. Real-Time PCR ( $q R T-P C R$ ) Analysis. Total RNA was isolated at various time points as indicated in the text and figure captions using TRIzol Reagent (Invitrogen) according to the manufacturer's protocol. The RNA concentration was determined using a NanoDrop2000 spectrophotometer (Thermo Scientific) and reverse transcription reactions were performed from $500 \mathrm{ng}$ of total RNA using a first cDNA synthesis kit (Fermentas). Real-time PCR reactions were conducted using SYBR green reagent (Invitrogen).

Primer sequences were listed in Table 1. Real-time PCR reactions were performed using the Chromo4 real-time PCR system (Bio-Rad). Samples were held at $95^{\circ} \mathrm{C}$ for $10 \mathrm{~min}$, followed by 40 amplification cycles consisting of a denaturation 
step at $95^{\circ} \mathrm{C}$ for $15 \mathrm{~s}$ and an annealing and extension step at $60^{\circ} \mathrm{C}$ for $1 \mathrm{~min}$. The threshold cycle values of the gene were normalized against Hprt and Ppia. Then the relative fold change was obtained by normalizing the data of each group against control group.

2.6. Alcian Blue Staining. After 21 days of culture, cells were fixed in $10 \%$ neutral buffered formalin and washed twice with PBS. Alcian Blue (Biosharp) staining was performed to detect proteoglycan. Samples were stained with 1\% Alcian Blue 8GS (Fluka) in $0.1 \mathrm{MHCl}$ for $5 \mathrm{~min}$ at room temperature.

2.7. Statistical Analysis. Repetitive ANOVA and Tukey's multiple comparison tests were used to determine statistical significance $(P<0.05)$ between groups. Experiments were repeated with $n=3$ biological replicates and the results were represented as the mean \pm standard deviation.

\section{Results}

3.1. Cell Proliferation in GM, IM, and CM. ATDC5 cells were cultured in GM, IM, and CM for 14 days. At various time points, the amount of cells in different groups was determined using CCK-8 kit and PicoGreen dsDNA kit. As shown in Figure 1, at the beginning of cell culture, cells in all the three groups showed almost the same proliferation rate. With time, cells in IM group grew rapidly and exhibited the highest proliferation rate among the three groups. The amount of cells in IM group was maintained after day 10. Cells in GM groups also kept proliferating at a moderate speed until day 7 while the cells in CM group grew at the lowest rate and ceased proliferation after day 5 . The data of dsDNA quantification shown in Figure 2 indicated a similar result. The quantity of dsDNA content in IM group was the highest among all the groups at day 3, day 5, and day 14, suggesting that IM promoted the proliferation of cells significantly. These data were consistent with the morphology of cells observed under the light microscope (Figure 3). At day 5, cells in IM and GM appeared about $90 \%$ confluence while those in CM gathered in to several rounded clumps.

3.2. Gene Expression Analysis in GM, IM, and CM. Collagen type II (Col2) and aggrecan (Agn), cartilage specific markers, were putatively used to evaluate the degree of chondrocyte differentiation. As shown in Figure 4, ATDC5 cells cultured in CM exhibited much higher expression level of Col2 and Agn from day 1 to day 7 compared with those cultured in IM and GM. Cells in IM group expressed Col2 and Agn in a similar level to those in GM from day 1 to day 5. At day 7, there appeared more Col2 and Agn expression in IM group than that in GM group.

Additionally, the expression level of hypertrophic marker genes including collagen type X (Col10), alkaline phosphatase (ALP), collagen type I (Coll), vascular endothelial growth factor (VEGF), and osteogenic target transcription factors Dlx5, Runx2, osterix (Osx), and osteocalcin (OC) were determined using qRT-PCR and compared between IM and CM groups (Figure 5). The data demonstrated that IM promoted

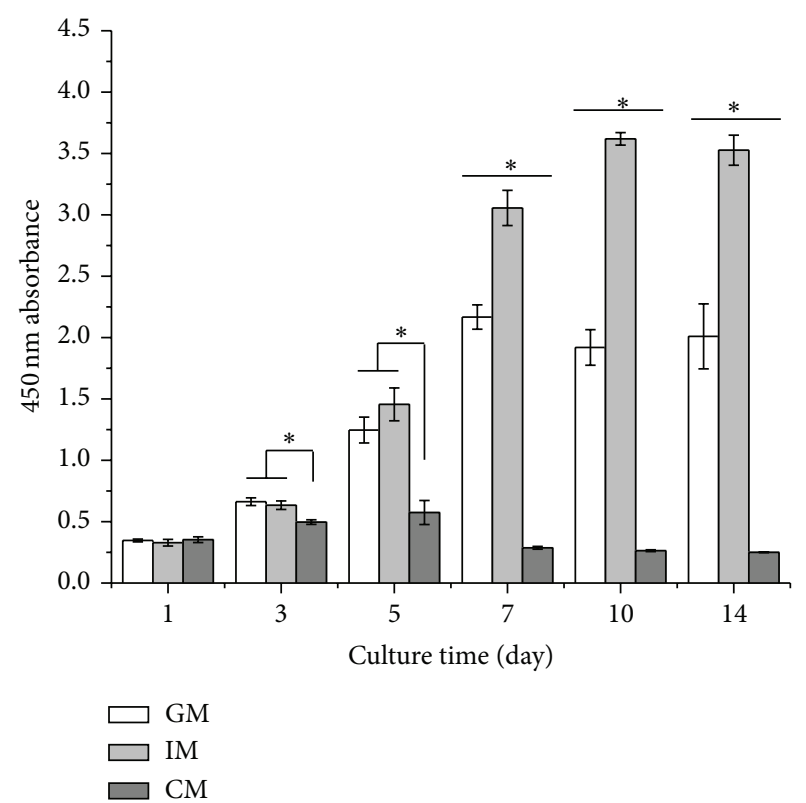

FIgure 1: Proliferation of cells cultured in different media. Cells were cultured in GM, IM, and CM for 14 days. At each time point, cell number was determined using CCK- 8 cell proliferation/cell viability kit. The amount of cells would be proportional to the absorbance at $450 \mathrm{~nm}$. The results were presented as the means \pm standard deviation $(n=6)$. ${ }^{*}$ Significant difference $(P<0.05)$ between groups at same time point.

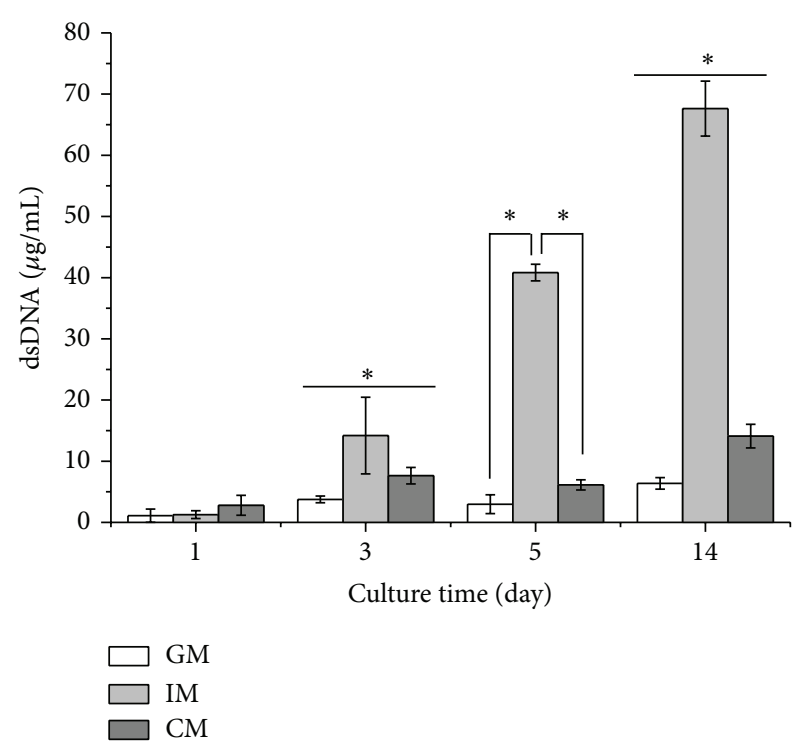

FIGURE 2: dsDNA quantification of cells cultured in different media. Cells were cultured in GM, IM, and CM for 14 days. At each time point, dsDNA content was detected by PicoGreen dsDNA kit. The amount of dsDNA content was directly in proportion to the cell number. The data were presented as the means \pm standard deviation $(n=4) .{ }^{*}$ Significant difference $(P<0.05)$ between groups at same time point. 


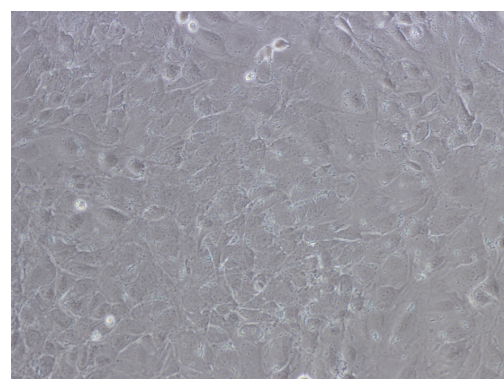

(a)

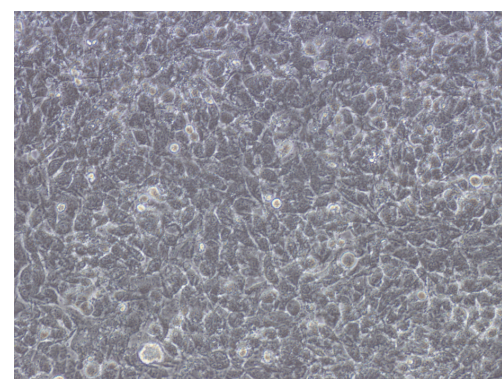

(b)

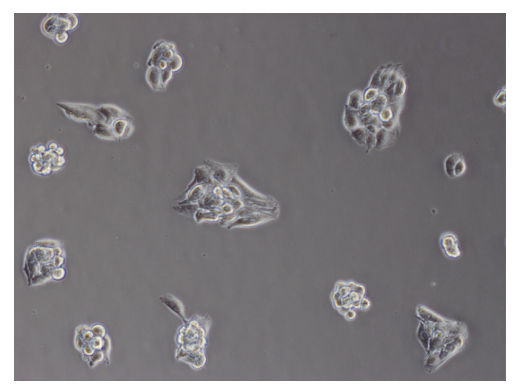

(c)

FIGURE 3: Morphology of ATDC5 cells cultured in (a) GM, (b) IM, and (c) CM at day 5. The pictures were taken under light microscope with 10x magnification.

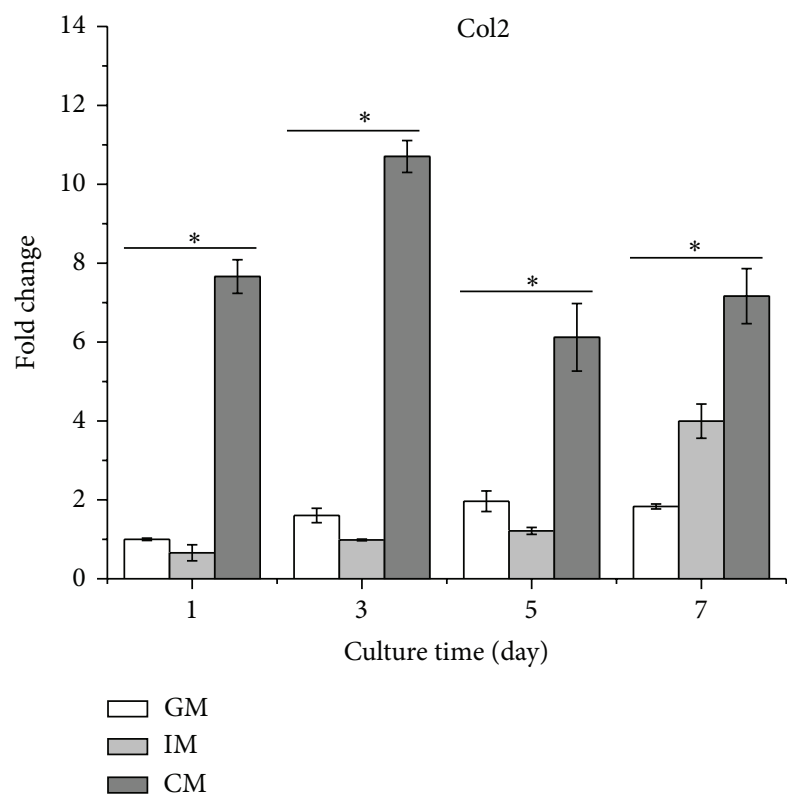

(a)

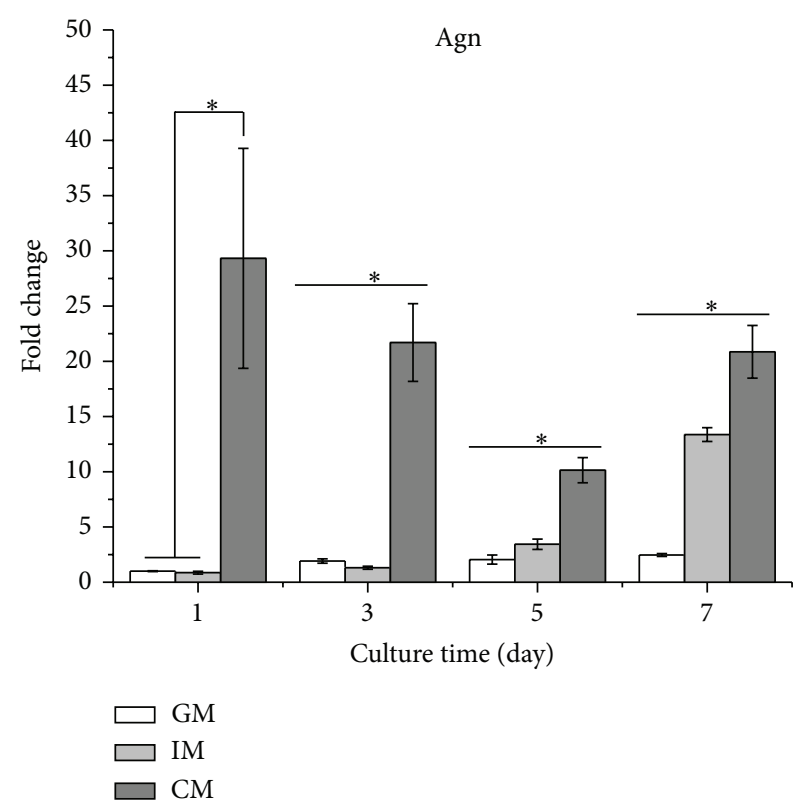

(b)

FIGURE 4: Expression level of chondrocyte specific genes of ATDC5 cells. Cells were cultured in CM and IM for 7 days. At the indicated time point, total RNA in all the three groups was isolated using TRIzol followed by PCR assay to evaluate the expression level of (a) Col2 and (b) Agn. The results were presented as the means \pm standard deviation $(n=3)$. ${ }^{*}$ Significant difference $(P<0.05)$ versus GM group.

the expression of all the above-mentioned genes of ATDC5 cells in comparison with CM.

3.3. Analysis of GAG Deposition. GAG is a typical component of cartilaginous ECM. Our results showed that the level of GAG deposition per cell in CM group was significantly higher than that in GM and IM (Figure 6(a)). Interestingly, the total GAG contents of cells cultured in IM were the most among all the three groups, as evidenced by the most intensive staining shown in Figure 6(b).

3.4. Selection for TGF- $\beta 3$ Concentration. It was shown in Figure 7 that cells appeared agglomerate with escalating concentration of TGF- $\beta 3$ at day 3. The data of qPCR (Figure 8 ) indicated that the expression level of Col2 and Agn in $10 \mathrm{ng} / \mathrm{mL}$ of TGF- $\beta 3$ was superior to that in other concentrations of TGF- $\beta 3$. On the other hand, $2 \mathrm{ng} / \mathrm{mL}$ TGF$\beta 3$ was sufficient to inhibit the expression of Collo and ALP, while the inhibition effects showed no significant difference with the increasing TGF- $\beta 3$ concentration. Taken together with all these data, $10 \mathrm{ng} / \mathrm{mL}$ was regarded as an optimal concentration to induce the chondrogenesis and prohibit the formation of hypertrophic chondrocyte.

\section{Discussion}

At present, people pin their hopes on stem cells with tissue engineering technology to cure osteochondral defect. However, numerous issues are still interfering with researchers. A lot of factors such as cell source [17-19], culture conditions [20-22], and stress [23-25], have various effects on osteochondral differentiation. Therefore, it is necessary to 


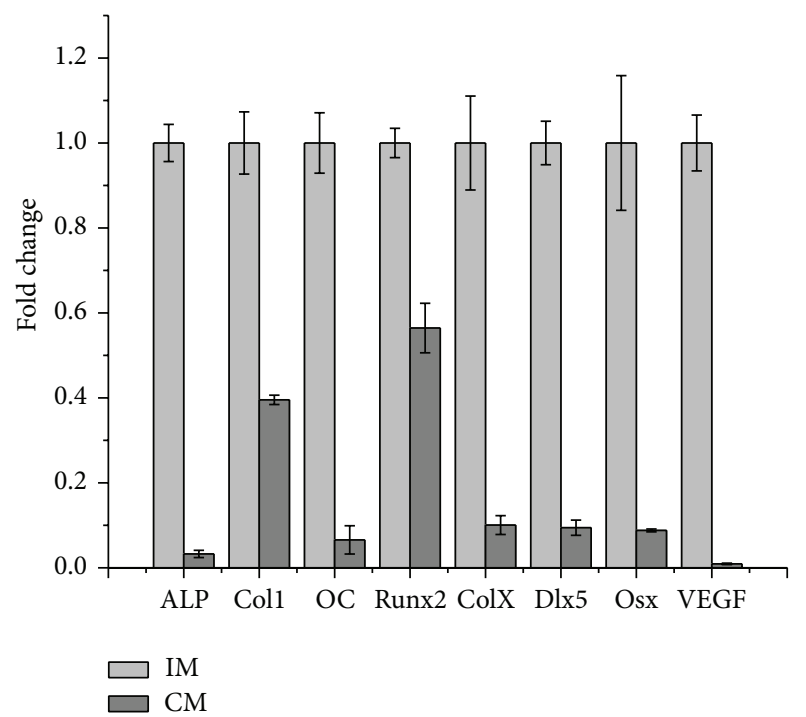

FIGURE 5: Expression level of endochondral ossification related genes of ATDC5 cells induced in IM and CM at day 14. The results were presented as the means \pm standard deviation $(n=3)$. Expression fold change of all genes had significant difference $(P<$ 0.05 ) between IM and CM.

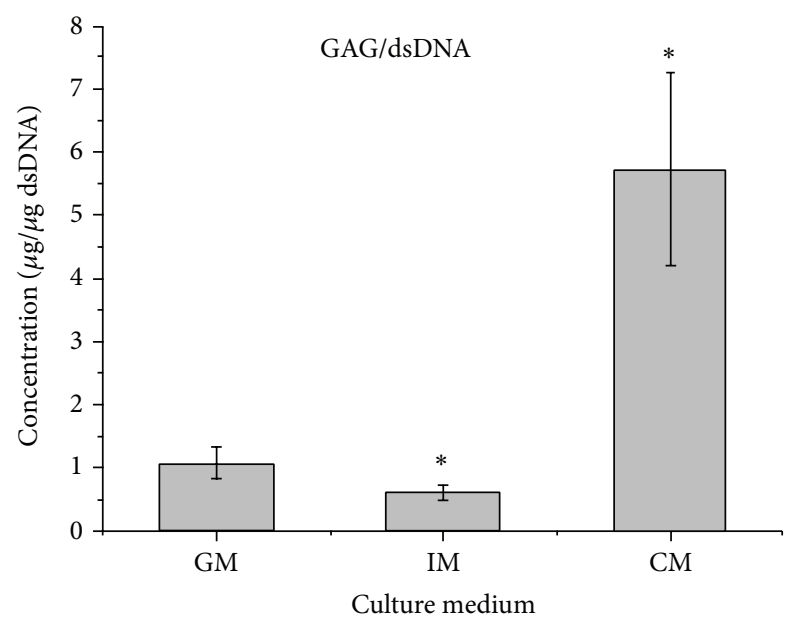

(a)

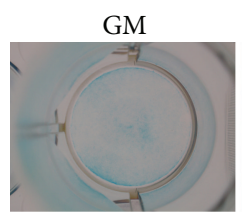

IM

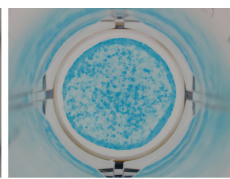

(b)

FIgURE 6: Analysis of GAG deposition of ATDC5 cells cultured in GM, IM, and CM for $21 \mathrm{~d}$. (a) Quantitative analysis of GAGs synthesis using the 1,9-dimethylmethylene blue method. (b) Alcian Blue staining. The results were presented as the means \pm standard deviation $(n=6)$. There was significant difference $(P<0.05)$ versus GM group. set up a model system to find out the optimal parameters so that suitable microenvironment would be established for chondrogenesis of stem cells. Among various kinds of cell lines, the ATDC 5 cell line has attracted much more attention as a model cell line for chondrocyte differentiation studies because of its excellent characteristics including easy culture, rapid proliferation, and maintenance of undiferentiation and homogeneity under normal culture conditions [26].

In this study, to investigate the effect of different medium on osteochondral differentiation, ATDC5 cells were cultured in monolayer which would remove the influences of the morphological and structural differences of scaffolds. The data of CCK-8 assay and dsDNA content test (shown in Figures 1 and 2) demonstrated that IM significantly accelerated the proliferation rate of cells. Cells cultured in CM were inclined to agglomerate at a slow growth rate (Figure 3). It was shown in Figure 4 that the expression of cartilage markers (Col2 and Agn) in CM group was remarkably enhanced at day 1 compared with GM group, whereas there was no obvious difference for expression level of Col2 and Agn between GM and IM until day 7. This result suggested that CM induced the chondrogenesis of ATDC5 cells sooner than IM did. And owing to the decrease of cell proliferation by differentiation process, cells in CM group grew much slower than those in IM group. Moreover, CM was favorable for inhibition of hypertrophy while IM promoted the expression of endochondral ossification related genes (Figure 5). And it was interesting that the level of GAG deposition per cell in $\mathrm{CM}$ group was the highest among all the groups whereas the greatest quantity of total GAG belonged to IM group, which was attributed to the vast amount of cells in IM group.

In addition, the preferable concentration of TGF- $\beta 3$ to obtain effective chondrocyte differentiation and avoid hypertrophy was selected as $10 \mathrm{ng} / \mathrm{mL}$ using ATDC 5 cells. TGF- $\beta 3$ could promote chondrocytic differentiation when in the right concentration. There would be no significant effect on chondrogenesis when too low TGF- $\beta 3$ concentration was applied. However, excessive supply of TGF- $\beta 3$ would not be effective in inducing chondrogenesis either. TGF beta could promote BMP signaling pathways while BMP2 significantly decreased TGF signaling pathways [27]. Buxton et al. found that temporal exposure of chondrogenic factor would lead to more production of cartilaginous matrix than continuous exposure did [28]. Therefore, neither the higher nor the longer treatment of growth factor would be beneficial for chondrogenesis. But studies are needed to figure out the optimal way to deliver chondrogenic factors. In addition, TGF beta could inhibit hypertrophy of cells and osteochondral ossification [29]. Low concentration of TGF beta could restrain the expression of Col10 and ALP. But with the increase of concentration, no obvious change appeared. And the data was consistent with other studies for chondrogenesis of mesenchymal stem cells (MSCs), suggesting the result obtained from study of ATDC 5 cells could apply to that of MSCs too.

A suitable cell density is required for chondrocytic differentiation. To some extent, higher density of cells was more beneficial for chondrogenesis than lower density did. Based on the above results, we believed IM and CM could be 


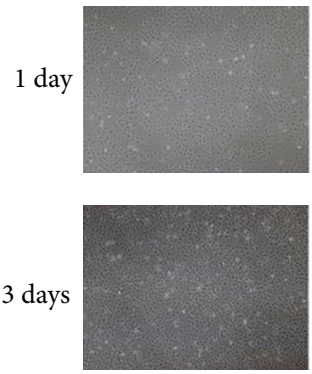

0
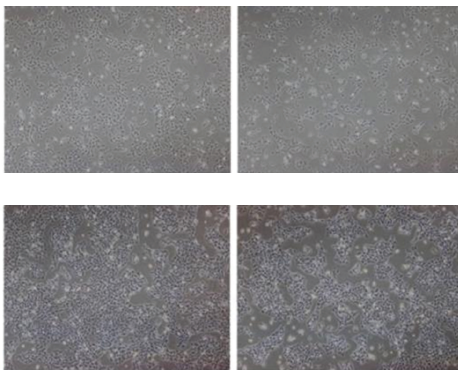

2

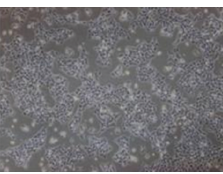

5

TGF- $\beta 3$ concentration $(\mathrm{ng} / \mathrm{mL})$

(a)
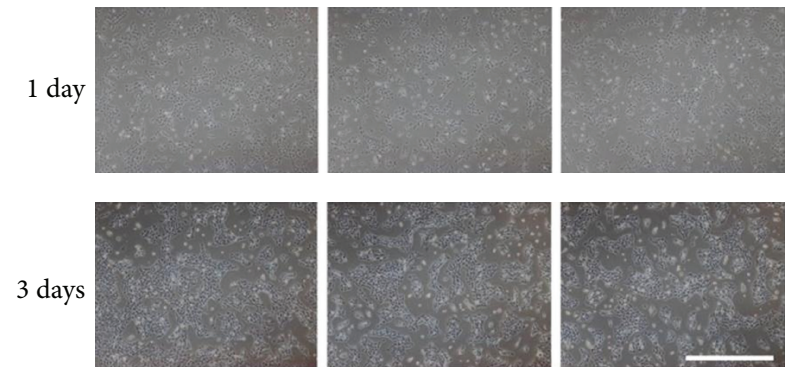

10

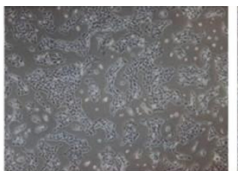

20

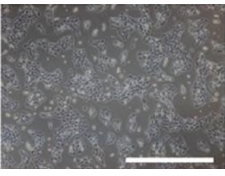

50

TGF- $\beta 3$ concentration $(\mathrm{ng} / \mathrm{mL})$

(b)

FIGURE 7: Cell morphology of ATDC5 cells cultured in CM with different TGF- $\beta 3$ concentration at day 3. Bar $=500 \mu \mathrm{m}$.

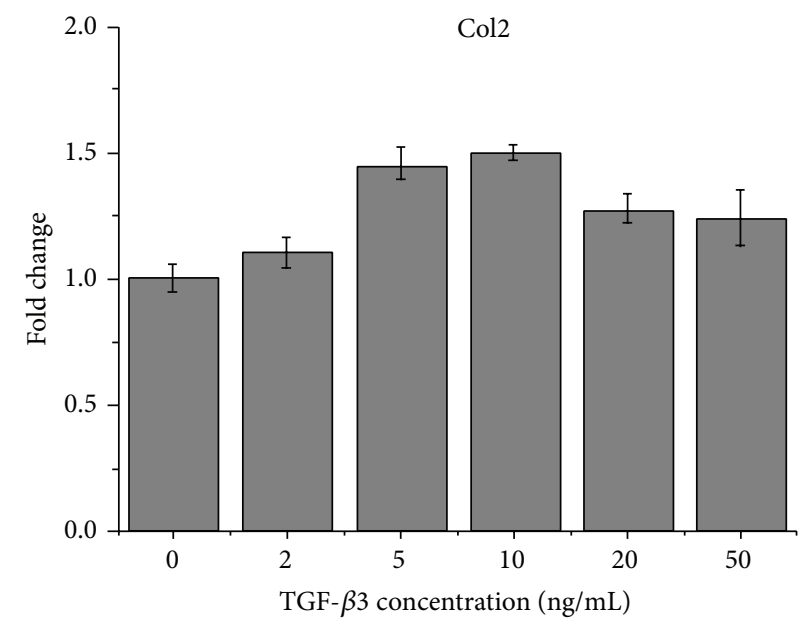

(a)

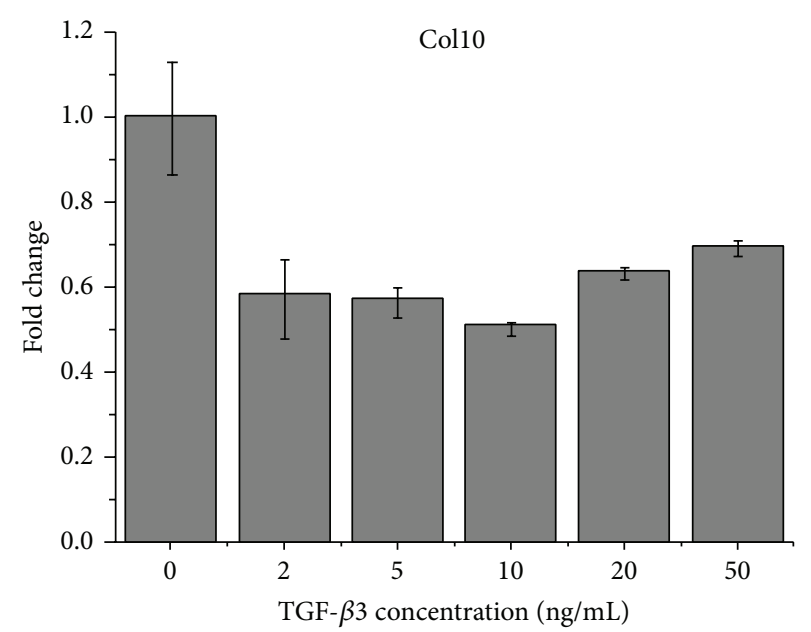

(c)

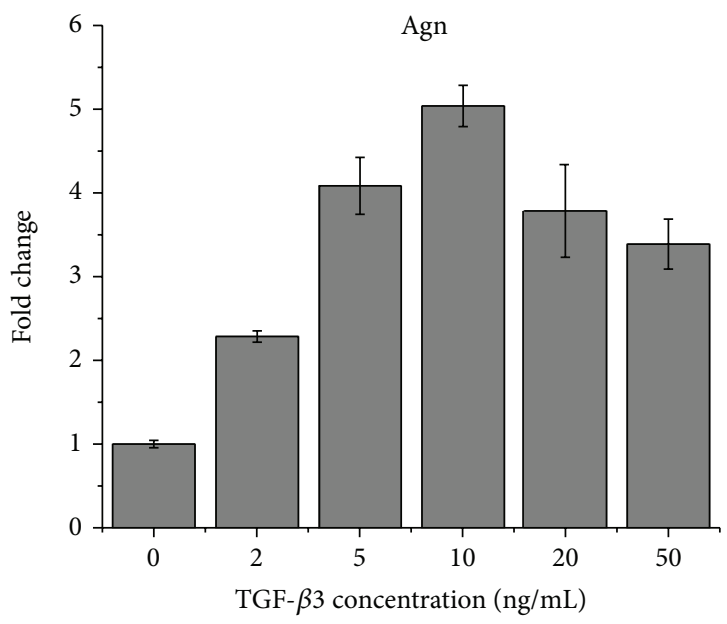

(b)

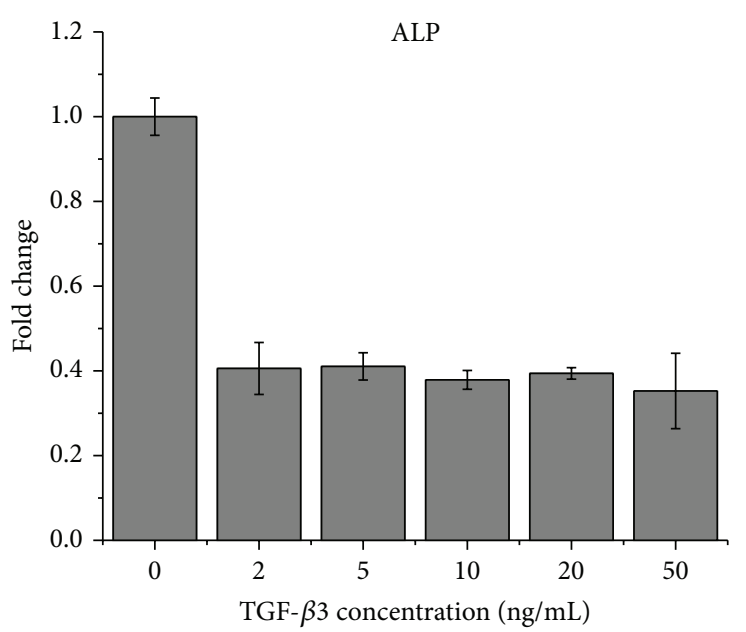

(d)

FIGURE 8: Gene expression level of ATDC5 cells cultured in CM with different TGF- $\beta 3$ concentration at day 14 . The results were presented as the means \pm standard deviation $(n=3)$. 
combined to induce the chondrogenesis for better outcome. IM would be used first to accelerate the cell growth and then would be replaced by CM for chondrocyte differentiation and suppression of endochondral ossification. More work would be needed to find out the suitable parameters.

Lots of studies have used ATDC 5 cells to explore the influence of other factors on chondrogenesis, including laser irradiation [30], oxygen [31, 32], and mechanical interaction $[33,34]$. Besides chondrogenesis, ATDC 5 cells would be also used as model cells for endochondral ossification [35]. With the use of stable model system, some parameters such as suitable seeding densities and selection of biological molecules would be optimized and the underlying mechanisms involved in the process of endochondral ossification would be elucidated. Thus, with gradual understanding of influence of various factors on endochondral ossification, favorable microenvironment could be established for bone/cartilage repair.

\section{Conflict of Interests}

The authors declare that there is no conflict of interests regarding the publication of this paper.

\section{Authors' Contribution}

Yongchang Yao and Zhichen Zhai contributed equally to this work.

\section{Acknowledgments}

This work was financially supported by the National Basic Research Program of China (Grant nos. 2012CB619100 and 2011CB606204), the National Natural Science Foundation of China (Grant nos. 51303058 and 51232002), the 111 project (B13039), and SRF for ROCS, SEM.

\section{References}

[1] P. B. Saadeh, B. Brent, B. J. Mehrara et al., "Human cartilage engineering: chondrocyte extraction, proliferation, and characterization for construct development," Annals of Plastic Surgery, vol. 42, no. 5, pp. 509-513, 1999.

[2] D. Nesic, R. Whiteside, M. Brittberg, D. Wendt, I. Martin, and P. Mainil-Varlet, "Cartilage tissue engineering for degenerative joint disease," Advanced Drug Delivery Reviews, vol. 58, no. 2, pp. 300-322, 2006.

[3] H. Koga, L. Engebretsen, J. E. Brinchmann, T. Muneta, and I. Sekiya, "Mesenchymal stem cell-based therapy for cartilage repair: a review," Knee Surgery, Sports Traumatology, Arthroscopy, vol. 17, no. 11, pp. 1289-1297, 2009.

[4] J. Ankrum and J. M. Karp, "Mesenchymal stem cell therapy: two steps forward, one step back," Trends in Molecular Medicine, vol. 16, no. 5, pp. 203-209, 2010.

[5] D. Bosnakovski, M. Mizuno, G. Kim et al., "Chondrogenic differentiation of bovine bone marrow mesenchymal stem cells in pellet cultural system," Experimental Hematology, vol. 32, no. 5, pp. 502-509, 2004.
[6] E.-J. Jin, K. S. Park, D. Kim et al., “TGF-beta3 inhibits chondrogenesis by suppressing precartilage condensation through stimulation of $\mathrm{N}$-cadherin shedding and reduction of cRREB1 expression," Molecules and Cells, vol. 29, no. 4, pp. 425-432, 2010.

[7] E. A. Lin, L. Kong, X.-H. Bai, Y. Luan, and C.-J. Liu, "MiR-199a", a bone morphogenic protein 2-responsive MicroRNA, regulates chondrogenesis via direct targeting to Smad1," The Journal of Biological Chemistry, vol. 284, no. 17, pp. 11326-11335, 2009.

[8] T. Atsumi, Y. Miwa, K. Kimata, and Y. Ikawa, "A chondrogenic cell line derived from a differentiating culture of AT805 teratocarcinoma cells," Cell Differentiation and Development, vol. 30, no. 2, pp. 109-116, 1990.

[9] A. Spagnoli, V. Hwa, W. A. Horton et al., "Antiproliferative effects of insulin-like growth factor-binding protein-3 in mesenchymal chondrogenic cell line RCJ3.1C5.18. Relationship to differentiation stage," The Journal of Biological Chemistry, vol. 276, no. 8, pp. 5533-5540, 2001.

[10] D. Panda, D. Goltzman, H. Jüppner, and A. C. Karaplis, "TIP39/parathyroid hormone type 2 receptor signaling is a potent inhibitor of chondrocyte proliferation and differentiation," American Journal of Physiology-Endocrinology and Metabolism, vol. 297, no. 5, pp. E1125-E1136, 2009.

[11] M. Fujii, K. Takeda, T. Imamura et al., "Roles of bone morphogenetic protein type I receptors and Smad proteins in osteoblast and chondroblast differentiation," Molecular Biology of the Cell, vol. 10, no. 11, pp. 3801-3813, 1999.

[12] S.-W. Tsai, H.-M. Liou, C.-J. Lin et al., "MG63 osteoblast-like cells exhibit different behavior when grown on electrospun collagen matrix versus electrospun gelatin matrix," PLoS ONE, vol. 7, no. 2, Article ID e31200, 2012.

[13] J. Jadlowiec, H. Koch, X. Zhang, P. G. Campbell, M. Seyedain, and C. Sfeir, "Phosphophoryn regulates the gene expression and differentiation of NIH3T3, MC3T3-E1, and human mesenchymal stem cells via the integrin/MAPK signaling pathway," The Journal of Biological Chemistry, vol. 279, no. 51, pp. 53323-53330, 2004.

[14] C. Shukunami, K. Ishizeki, T. Atsumi, Y. Ohta, F. Suzuki, and Y. Hiraki, "Cellular hypertrophy and calcification of embryonal carcinoma-derived chondrogenic cell line ATDC5 in vitro," Journal of Bone and Mineral Research, vol. 12, no. 8, pp. 11741188, 1997.

[15] R. S. Tare, D. Howard, J. C. Pound, H. I. Roach, and R. O. C. Oreffo, "ATDC5: an ideal cell line for development of tissue engineering strategies aimed at cartilage generation," European Cells and Materials, vol. 10, supplement 2, p. 22, 2005.

[16] R. W. Farndale, D. J. Buttle, and A. J. Barrett, "Improved quantitation and discrimination of sulphate glycosaminoglycans by use of dimethylmethylene blue," Biochimica et Biophysica Acta-General Subjects, vol. 883, no. 2, pp. 173-177, 1986.

[17] S. Choi, T. J. Cho, S. K. Kwon, G. Lee, and J. Cho, "Chondrogenesis of periodontal ligament stem cells by transforming growth factor-beta3 and bone morphogenetic protein- 6 in a normal healthy impacted third molar," International Journal of Oral Science, vol. 5, pp. 7-13, 2013.

[18] T. Vinardell, E. J. Sheehy, C. T. Buckley, and D. J. Kelly, "A comparison of the functionality and in vivo phenotypic stability of cartilaginous tissues engineered from different stem cell sources," Tissue Engineering A, vol. 18, pp. 1161-1170, 2012.

[19] A. M. Fernandes, S. R. Herlofsen, T. A. Karlsen, A. M. Kuchler, Y. Floisand, and J. E. Brinchmann, "Similar properties of chondrocytes from osteoarthritis joints and mesenchymal stem 
cells from healthy donors for tissue engineering of articular cartilage," PLoS One, vol. 8, no. 5, Article ID e62994, 2013.

[20] M. Pei, Y. Zhang, J. Li, and D. Chen, "Antioxidation of decellularized stem cell matrix promotes human synovium-derived stem cell-based chondrogenesis," Stem Cells and Development, vol. 22, pp. 889-900, 2013.

[21] Z. Yin, X. Chen, J. L. Chen et al., "The regulation of tendon stem cell differentiation by the alignment of nanofibers," Biomaterials, vol. 31, no. 8, pp. 2163-2175, 2010.

[22] Y. Yao, F. Zhang, R. Zhou, K. Su, J. Fan, and D.-A. Wang, "Effects of combinational adenoviral vector-mediated TGF $\beta 3$ transgene and shRNA silencing type I collagen on articular chondrogenesis of synovium-derived mesenchymal stem cells," Biotechnology and Bioengineering, vol. 106, no. 5, pp. 818-828, 2010.

[23] A. J. Steward, S. D. Thorpe, T. Vinardell, C. T. Buckley, D. R. Wagner, and D. J. Kelly, "Cell-matrix interactions regulate mesenchymal stem cell response to hydrostatic pressure," Acta Biomaterialia, vol. 8, no. 6, pp. 2153-2159, 2012.

[24] S. D. Waldman, C. G. Spiteri, M. D. Grynpas, R. M. Pilliar, and R. A. Kandel, "Long-term intermittent compressive stimulation improves the composition and mechanical properties of tissueengineered cartilage," Tissue Engineering, vol. 10, no. 9-10, pp. 1323-1331, 2004.

[25] J. Li, J. Wang, Y. Zou et al., "The influence of delayed compressive stress on TGF-betal-induced chondrogenic differentiation of rat BMSCs through Smad-dependent and Smadindependent pathways," Biomaterials, vol. 33, pp. 8395-8405, 2012.

[26] Y. Yao and Y. Wang, "ATDC5: an excellent in vitro model cell line for skeletal development," Journal of Cellular Biochemistry, vol. 114, pp. 1223-1229, 2013.

[27] B. Keller, T. Yang, Y. Chen et al., "Interaction of TGF $\beta$ and bmp signaling pathways during chondrogenesis," PLoS ONE, vol. 6, no. 1, Article ID e16421, 2011.

[28] A. N. Buxton, C. S. Bahney, J. U. Yoo, and B. Johnstone, "Temporal exposure to chondrogenic factors modulates human mesenchymal stem cell chondrogenesis in hydrogels," Tissue Engineering A, vol. 17, no. 3-4, pp. 371-380, 2011.

[29] X. Yang, L. Chen, X. Xu, C. Li, C. Huang, and C.-X. Deng, "TGF$\beta / \mathrm{Smad} 3$ signals repress chondrocyte hypertrophic differentiation and are required for maintaining articular cartilage," Journal of Cell Biology, vol. 153, no. 1, pp. 35-46, 2001.

[30] T. Kushibiki, T. Tajiri, Y. Ninomiya, and K. Awazu, "Chondrogenic mRNA expression in prechondrogenic cells after blue laser irradiation," Journal of Photochemistry and Photobiology B: Biology, vol. 98, no. 3, pp. 211-215, 2010.

[31] L. Chen, T. Fink, P. Ebbesen, and V. Zachar, "Optimized chondrogenesis of ATCD5 cells through sequential regulation of oxygen conditions," Tissue Engineering, vol. 12, no. 3, pp. 559$567,2006$.

[32] R. Zaka, A. S. Dion, A. Kusnierz et al., "Oxygen tension regulates the expression of ANK (progressive ankylosis) in an HIF-1dependent manner in growth plate chondrocytes," Journal of Bone and Mineral Research, vol. 24, no. 11, pp. 1869-1878, 2009.

[33] Y. Xing, Y. Gu, R. R. Gomes Jr., and J. You, "P2Y $Y_{2}$ receptors and GRK2 are involved in oscillatory fluid flow induced ERK1/2 responses in chondrocytes," Journal of Orthopaedic Research, vol. 29, no. 6, pp. 828-833, 2011.

[34] Y. Kambe, N. Hayashi, and N. Tomita, "Adhesive force behavior of single ATDC5 cells in chondrogenic culture," Biochemical and Biophysical Research Communications, vol. 420, no. 2, pp. 241-246, 2012.

[35] J. Guicheux, G. Palmer, C. Shukunami, Y. Hiraki, J. P. Bonjour, and J. Caverzasio, "A novel in vitro culture system for analysis of functional role of phosphate transport in endochondral ossification," Bone, vol. 27, no. 1, pp. 69-74, 2000. 


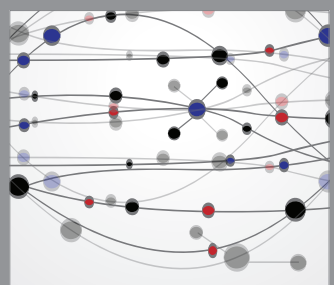

The Scientific World Journal
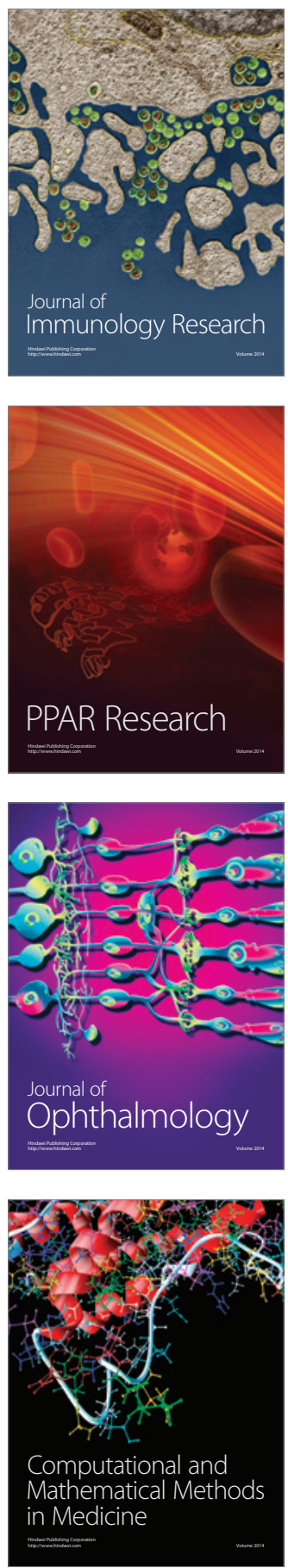

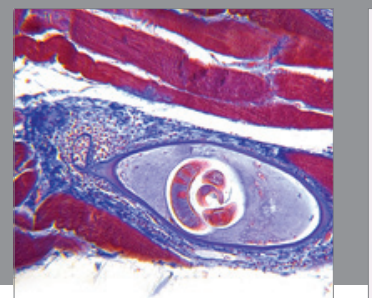

Gastroenterology

Research and Practice
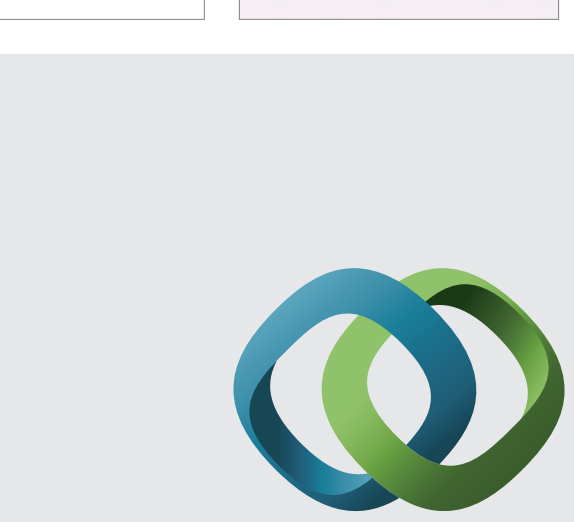

\section{Hindawi}

Submit your manuscripts at

http://www.hindawi.com
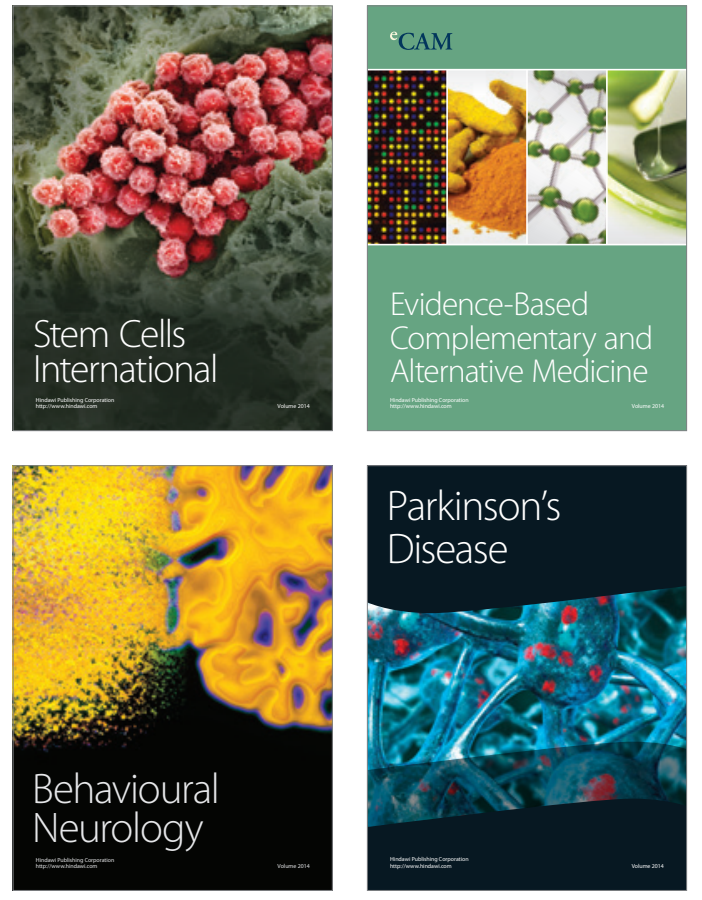
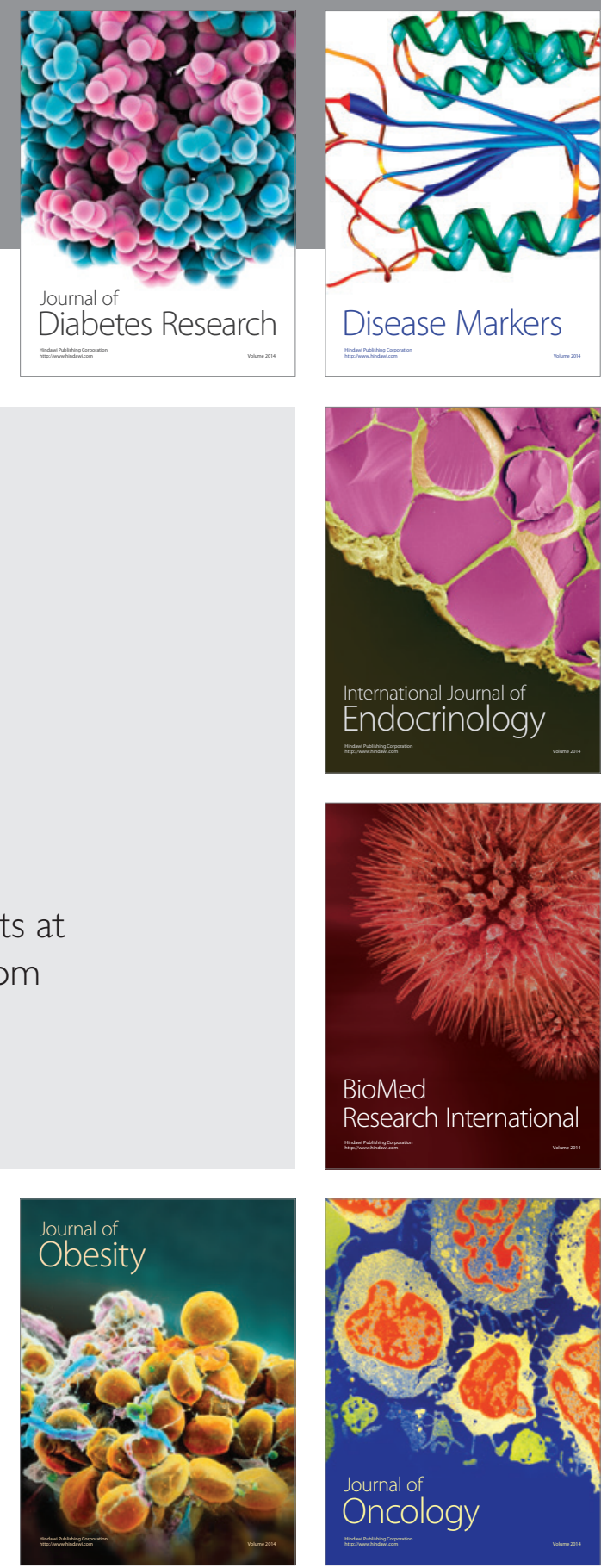

Disease Markers
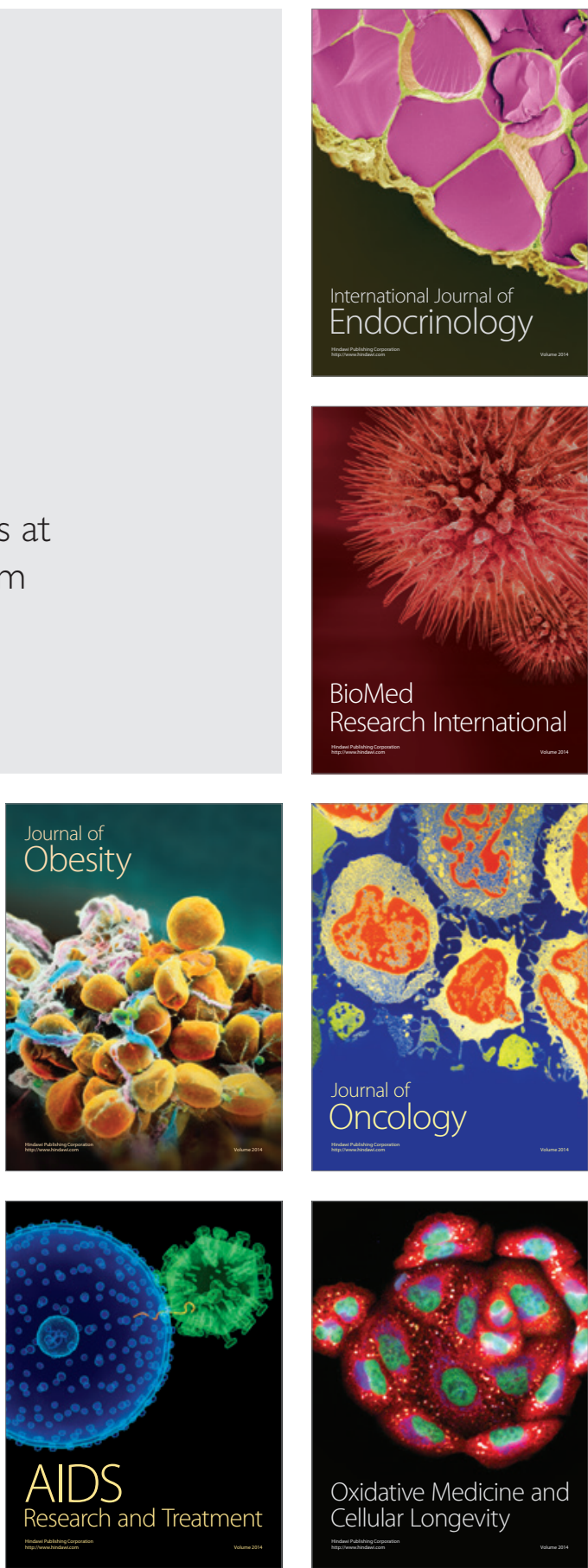